\title{
Severe Symptomatic Hypocalcaemia Following High-Dose Oral Ibandronate in a Patient With Prior Thyroidectomy and Metastatic Bone Disease
}

\author{
Daniel Litu Chen ${ }^{\mathrm{a}, \mathrm{c}}$, Amanda Goldrick ${ }^{\mathrm{b}}$, Jerry R. Greenfield ${ }^{\mathrm{a}}$
}

\begin{abstract}
Ibandronate is used to treat bony metastatic disease and hypercalcaemia of malignancy. We report the first case of severe hypocalcaemia following oral ibandronate. A 65-year-old woman with widespread sclerotic bony metastases due to breast cancer was commenced on oral ibandronate (50 mg daily). The corrected calcium level decreased from $2.11 \mathrm{mmol} / \mathrm{L}$ to $1.38 \mathrm{mmol} / \mathrm{L}$ (2.1 - 2.6 $\mathrm{mmol} / \mathrm{L}$ ) accompanied by lower leg muscle cramps 3 weeks after initiation of ibandronate therapy. She had an inappropriately normal PTH level of $6.8 \mathrm{pmol} / \mathrm{L}(1-7 \mathrm{pmol} / \mathrm{L})$ with normal $25-\mathrm{OH}$ vitamin D level of $59 \mathrm{nmol} / \mathrm{L}$ and normal magnesium level of 0.88 $\mathrm{mmol} / \mathrm{L}(0.7-1.05 \mathrm{mmol} / \mathrm{L})$. There was a history of previous total thyroidectomy for multinodular goitre. Intermittent calcium infusion was required to maintain the corrected calcium level around 1.9 - $2 \mathrm{mmol} / \mathrm{L}$ over the next 3 weeks. The patient was discharged on calcium citrate $250 \mathrm{mg}$ tds and calcitriol $0.5 \mathrm{mcg}$ qid with calcium level of $1.96 \mathrm{mmol} / \mathrm{L}$. We conclude that oral bisphosphonates are widely used but rarely associated with symptomatic severe hypocalcaemia. Possible mechanisms in this case include hypoparathyroidism and metastatic bone disease with widespread sclerosis. This case demonstrates that patients may devekop symptomatic hypocalcaemia when treated with oral bisphosphonates.
\end{abstract}

Keywords: Bony tissue neoplasm; Breast neoplasm; Hypocalcemia; Hypoparathyroidism; Ibandronic acid

Manuscript accepted for publication April 6, 2012

${ }^{a}$ Department of Endocrinology, St Vincent's Hospital, 390 Victoria Street, Darlinghurst, 2010, Sydney, Australia

${ }^{b}$ Department of Medical Oncology, St Vincent's Hospital, 390 Victoria Street, Darlinghurst, 2010, Sydney, Australia

${ }^{\mathrm{c}}$ Corresponding author: Daniel Litu Chen, Clinical Research Facility, Garvan Institute of Medical Research, 384 Victoria Street,

Darlinghurst, 2010, Sydney, Australia. Email: d.chen@garvan.org.au

doi:10.4021/jem96w

\section{Introduction}

Ibandronate is used to manage bony metastatic disease and hypercalcaemia of malignancy. Symptomatic hypocalcaemia has been described with oral alendronate [1]. This is the first case of severe hypocalcaemia following oral ibandronate therapy.

\section{Case Report}

The patient was a 65 -year-old lady who presented to our hospital with severe hypocalcaemia, 1 month after commencing ibandronate. Her past medical history included a left mastectomy for a $50 \mathrm{~mm}$ intraductal breast carcinoma (ER +ve, PR -ve) 20 years ago. She was treated with tamoxifen for three years. The patient had a total thyroidectomy for multinodular goitre six years prior to presentation. There was no evidence of parathyroid tissue on histopathology. However, she developed postoperative hypocalcaemia, with initial corrected calcium level of $1.85 \mathrm{mmol} / \mathrm{L}(2.1-2.6 \mathrm{mmol} / \mathrm{L})$. Calcium level increased to $2.01 \mathrm{mmol} / \mathrm{L}$ on discharge after 3 days of calcium carbonate (1 tablet/day).

The patient was diagnosed with widespread sclerotic bony metastases one month prior to the current presentation, when capecitabine and ibandronate $50 \mathrm{mg}$ daily were commenced.

After three weeks of ibandronate therapy, the patient developed lower limb muscle cramps but no other symptoms of hypocalcaemia. Chvostek and Trousseau's signs were absent. Corrected calcium level was $1.38 \mathrm{mmol} / \mathrm{L}$ (Fig. 1). Ionised calcium was $0.84 \mathrm{mmol} / \mathrm{L}(1.15-1.3 \mathrm{mmol} / \mathrm{L})$. PTH level was inappropriately normal at $6.8 \mathrm{pmol} / \mathrm{L}(1-7 \mathrm{pmol} / \mathrm{L})$ and $25-\mathrm{OH}$ vitamin D was $59 \mathrm{nmol} / \mathrm{L}$. Magnesium level was normal. Electrocardiography showed prolonged QTc interval of $492 \mathrm{~ms}$ (normal $<460 \mathrm{~ms}$ ). The patient was not taking other medications that may prolong the QTc interval. Prior to commencing ibandronate, the corrected serum calcium was 2.11 $\mathrm{mmol} / \mathrm{L}$ and $25-\mathrm{OH}$ vitamin $\mathrm{D}$ level was $87 \mathrm{nmol} / \mathrm{L}$ (normal range, $35-150 \mathrm{nmol} / \mathrm{L}$ ). Other medications include spironolactone, thyroxine and ondansetron. 


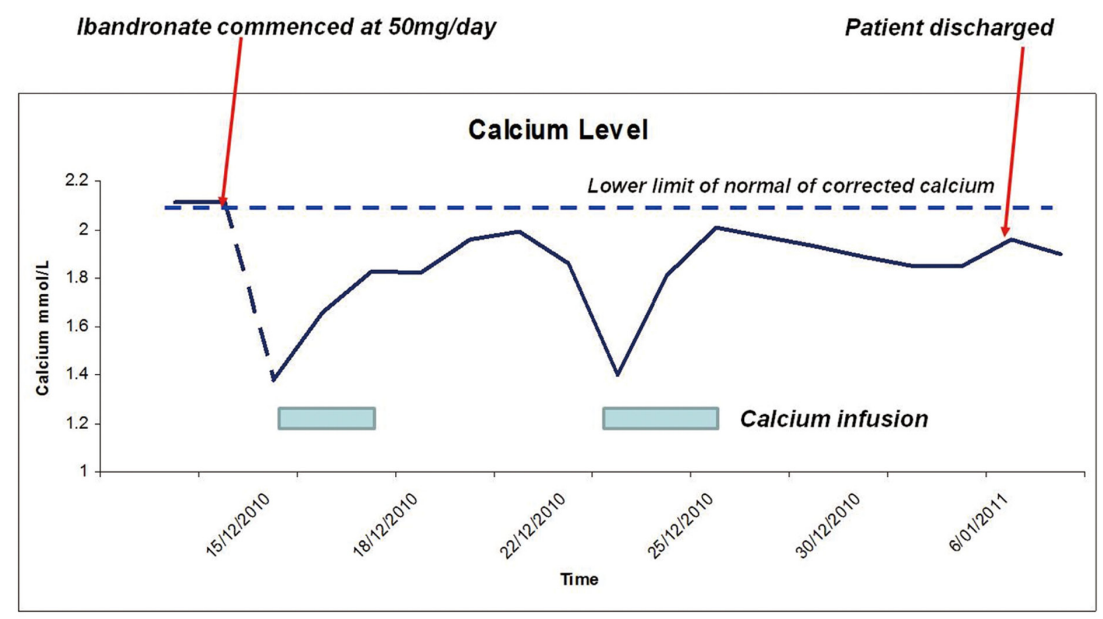

Figure 1. Serum Calcium levels.

The patient was treated with intravenous calcium gluconate twice with each infusion lasting approximately $48-72$ hours. She was eventually maintained on calcium citrate 250 $\mathrm{mg}$ tds and calcitriol $0.5 \mathrm{mcg}$ qid. Corrected calcium was $1.96 \mathrm{mmol} / \mathrm{L}$ on discharge. The patient continued to have persistent hypocalcaemia 2 months post discharge with corrected calcium level of $1.9 \mathrm{mmol} / \mathrm{L}$ (ionised calcium 0.86 $\mathrm{mmol} / \mathrm{L}$ ), necessitating continuation of the same dosage of calcium citrate and calcitriol.

\section{Discussion}

Bisphosphonates are widely used in malignancy to treat tumour-associated hypercalcaemia. In patients with metastatic bone disease these are agents given to relieve pain and reduce the risk of further skeletal events. Bisphosphonates are potent inhibitors of osteoclastic bone resorption [2]. Such inhibition causes transient hypocalcaemia and a compensatory increase in PTH secretion, which enhances intestinal calcium absorption through increased renal production of 1 , 25-dihydroxyvitamin D and distal renal tubular reabsorption of calcium.

Ibandronate is a nitrogen-containing bisphosphonate $(\mathrm{t}$ $1 / 2=10-60$ hours) that is more potent than alendronate, but less potent than risedronate and zoledronic acid [3]. In contrast to intravenous bisphosphonate therapy, oral bisphosphonates are rarely associated with symptomatic severe hypocalcaemia. Symptomatic hypocalcaemia has been rarely described with oral alendronate [1]. However, hypocalcaemia following oral ibandronate use has not been reported with the low doses ( $2.5 \mathrm{mg}$ daily or $150 \mathrm{mg}$ monthly) used in osteoporosis. The dose of ibandronate ( $50 \mathrm{mg}$ daily) in this patient is indicated for bone metastasis, which is much higher than the standard dose used for osteoporosis treatment.
Capecitabine has not been associated with the development of hypocalcaemia.

A possible contributor to severe hypocalcaemia in this case is relative hypoparathyroidism. We hypothesised that although some parathyroid tissue was probably removed during thyroidectomy, PTH secretion may have been sufficient to maintain normocalcaemia under basal conditions, but did not adequately increase in response to the hypocalcaemic stress. The patient described herein may have subclinical hypoparathyroidism that was unmasked by ibandronate therapy.

Another possible aetiology to hypocalcaemia in our case is entrapment of calcium by sclerotic bony metastases. This has previously been reported in association with prostate cancer [4]. There is one case report describing hypocalcaemia as an initial presentation in subject with breast cancer and osteoblastic metastases [5]. It is believed that hypocalcaemia is due to "hungry bone syndrome" driven by the sclerotic (osteoblastic) metastases forming excess bone and entrapping calcium. Therefore, it is more difficult to mobilise calcium into the blood after bisphosphonate administration. The persistence of hypocalcaemia many weeks after cessation of ibandronate suggests that bone metastasis and perhaps subclinical hypoparathyroidism were significant contributors to the development of hypocalcaemia in this patient. This is also supported by the presence of a low normal calcium level prior to ibandronate treatment.

\section{Conclusion}

This case demonstrates that patients unable to mount a compensatory parathyroid response may be at high risk of symptomatic hypocalcaemia when treated with oral bisphosphonates, particularly in the setting of sclerotic bony metastases. It may be prudent to check for risk factors for hypocalcaemia 
before prescribing bisphosphonates.

\section{References}

1. Schussheim DH, Jacobs TP, Silverberg SJ. Hypocalcemia associated with alendronate. Ann Intern Med. 1999;130(4 Pt 1):329.

2. Compston JE. The therapeutic use of bisphosphonates.
BMJ. 1994;309(6956):711-715.

3. Rizzoli R. Bisphosphonates for post-menopausal osteoporosis: are they all the same? QJM. 2011;104(4):281-300.

4. Tandon PK, Rizvi AA. Hypocalcemia and parathyroid function in metastatic prostate cancer. Endocr Pract. 2005;11(4):254-258.

5. Cooksley T, Banerjee M, Younis N. Metastatic breast carcinoma presenting with profound hypocalcemia. South Med J. 2010;103(5):480-481. 